\title{
Acanthocephala Larvae parasitizing Ameiva ameiva ameiva (Linnaeus, 1758) (Squamata: Teiidae)
}

\author{
Larvas de Acanthocephala parasitando Ameiva ameiva ameiva (Linnaeus, 1758) (Squamata:Teiidae) \\ Lilian Cristina Macedo ${ }^{1 *}$; Francisco Tiago de Vasconcelos Melo ${ }^{1}$; Teresa Cristina Sauer Ávila-Pires ${ }^{2}$; \\ Elane Guerreiro Giese ${ }^{3}$; Jeannie Nascimento dos Santos ${ }^{1}$ \\ ${ }^{1}$ Laboratório de Biologia Celular e Helmintologia "Profa. Dra. Reinalda Marisa Lanfredi", Instituto de Ciências Biológicas - ICB, \\ Universidade Federal do Pará - UFPA, Belém, PA, Brasil \\ ${ }^{2}$ Coordenação de Zoologia, Museu Paraense Emílio Goeldi - MPEG, Belém, PA, Brasil \\ ${ }^{3}$ Laboratório de Histologia e Embriologia Animal, Instituto da Saúde e Produção Animal - ISPA, Universidade Federal Rural da \\ Amazônia - UFRA, Belém, PA, Brasil
}

Received May 13, 2015

Accepted July 20, 2015

\begin{abstract}
Knowledge concerning the taxonomy and biology of species of Acanthocephala, helminth parasites of the helminth species of the phylum Acanthocephala, parasites of lizards in Brazilian Amazonia, is still insufficient, but reports of Acanthocephala in reptiles are becoming increasingly common in the literature. Cystacanth-stage Acanthocephalan larvae have been found in the visceral peritoneum during necropsy of Ameiva ameiva ameiva lizards from the "Osvaldo Rodrigues da Cunha" Herpetology Collection of the Emílio Goeldi Museum, Belém, Pará, Brazil. The aim of this study was to present the morphological study of the Acanthocephala larvae found in A. ameiva ameiva lizard.
\end{abstract}

Keywords: Amazonia, Oligacanthorhynchidae, cystacanths.

\section{Resumo}

O conhecimento a respeito da taxonomia e da biologia das espécies de Acanthocephala, helmintos parasitos das espécies de lagartos da Amazônia Brasileira ainda é insuficiente, mas o registro do encontro de acantocéfalos em répteis é cada vez mais comum na literatura. Foram encontradas larvas de acantocéfalos em fase cistacanto durante a necropsia, no peritônio visceral, de lagartos Ameiva ameiva ameiva provenientes da Coleção Herpetológica "Osvaldo Rodrigues da Cunha” do Museu Paraense Emílio Goeldi, Belém, Pará. O objetivo é apresentar um estudo morfológico de larvas de Acanthocephala encontradas em $A$. ameiva ameiva.

Palavras-chave: Amazônia, Oligacanthorhynchidae, cistacanto.

The phylum Acanthocephala Kohlreuther, 1771, consists of four classes: Polyacanthocephala Amin, 1987, Archiacanthocephala Meyer, 1931, Palaeacanthocephala Meyer, 1931, and Eoacanthocephala Van Cleave, 1936 (AMIN, 1987; AMIN, 2013). This group of obligate, parasitic helminths parasitizes invertebrates and vertebrates as intermediate and definitive hosts, respectively, during one or more stages in its lifecycle. Occasionally, to allow the helminth to complete its lifecycle, another type of host can be used as a bridge species to link the intermediate and definitive hosts. This host is known as a paratenic or transport host, i.e., it is a vertebrate host that does not allow the complete development of the parasite (SCHMIDT, 1985; ROBERTS \& JANOVY, 2009).

Ameiva ameiva ameiva (Linnaeus, 1758) lizards are widely distributed geographically, and of the seven known species in

*Corresponding author: Lilian Cristina Macedo. Laboratório de Biologia Celular e Helmintologia "Profa. Dra. Reinalda Marisa Lanfredi", Instituto de Ciências Biológicas, Universidade Federal do Pará - UFPA, Av. Augusto Correa s/n, 66075-900, Belém, PA, Brasil. e-mail: lcmacedo@ufpa.br this genus that occur in South America, only A. ameiva ameiva and Ameiva parecis Colli, Costa, Garda, Kopp, Mesquita, Péres, Valdujo, Vieira \& Wiederhecker, 2003, have been identified in Brazilian Amazonia, but the latter only in enclaves of open vegetation in the state of Rondônia (AVILA-PIRES, 1995; HARVEY et al., 2012; GIUGLIANO et al., 2013;). Ameiva ameiva ameiva has generalist diurnal habits and occupies both open and forested areas, which facilitates or leads to parasitism by several helminth species and makes it an excellent paratenic host (AVILA-PIRES, 1995; RIBAS et al., 1998; ÁVILA \& SILVA, 2010). The aim of this study was to present morphological aspects of the Acanthocephala larvae found in the visceral peritoneum during necropsy of $A$. ameiva ameiva.

Fifteen specimens of $A$. ameiva ameiva lizards, fixed in $10 \%$ formaldehyde and preserved in 70\% ethanol (10 male specimens and five female specimens), were obtained from the "Osvaldo Rodrigues da Cunha" Herpetology Collection of the Emílio Goeldi Museum (Museu Paraense Emílio Goeldi - MPEG). These hosts 
were originally collected in the Caxiuanã National Forest (Floresta Nacional de Caxiuanã - FLONA Caxiuanã), municipality of Portel, State of Pará, and were stored under the following registration numbers: MPEG26034 - 26036, 26038 - 26039, 26047, 26053, 26057, 26059 - 26061, 26066, 26071 and 26073 - 26074.

Lizards were necropsied and examined for helminths. The worms were cleared in glycerin following the protocol by Amato et al. (1991). Morphometry and morphological studies were made from three specimens with an everted proboscis and were performed following Richardson (2005) using an Olympus BX41 microscope equipped with a drawing tube without zoom. After morphometric analysis the specimen was prepared for scanning electron microscopy (SEM) following Giese et al. (2010) and examined using a LEO/1450VP Scanning Electron Microscope.

Cysts of larval acanthocephalans were found in nine specimens of A. ameiva ameiva for an average of 17 (2-53) cysts per host. Due to in loco preservation of the parasites, the taxonomic structures were damaged. However, diagnosis was still possible after dissection of all of the cysts. Thus, the larvae were stages, called infective stage, called the cystacanth stage, and surrounded by a hyaline envelope that is characterized as follows:

Cystacanth morphology (Using Light and Scanning Electron Microscopy, $\mathbf{n = 3}$ ): Body with tegument containing transverse striations measuring $3.36 \pm 0.60(3.03-5.70) \times 1.0 \mathrm{~mm}$ (Figure 1A) and a globular proboscis measuring $0.41(0.38-0.64)$ $\times 0.58(0.56-0.59) \mathrm{mm}$ with 48 hooks arranged in six oblique rows with eights hooks each [row counting and organization according proposed by Richardson (2005)], arranged with the largest hooks clearly placed on the apex and the smallest hooks at the base of the proboscis (Figure 1B-D; Figure 2A-D). Each row contained the following: two large hooks on the proboscis apex measuring an average of 157 (101-220) $\mu \mathrm{m}$ and 162 (133-173) $\mu \mathrm{m}$, three medium-sized hooks measuring 101 (85-112) $\mu \mathrm{m}$, $81(67-96) \mu \mathrm{m}$ and $85(80-93) \mu \mathrm{m}$, and three small hooks near the base of the proboscis with an average length of 53 (43-64) $\mu \mathrm{m}, 56$ (53-58) $\mu \mathrm{m}$ and 55 (53-57) $\mu \mathrm{m}$ (Figure 1B-D). Proboscis receptacle double-walled $0.91(0.82-1.03) \times 0.36(0.33-0.40) \mathrm{mm}$, not inserted in the anterior region of the body. Prevalence: $60 \%$. Range of infection: 2-53. Registration number: MPEG 0001.

Study of morphological features using by light microscopy and scanning electron microscopy revealed that the specimens of larval Acanthocephala found during the cystacanth stage in the visceral peritoneum of the $A$. ameiva ameiva host had characteristics typical of the family Oligacanthorhynchidae. The specimens were assigned to the Class Archiacanthocephala because they have a globular proboscis with a small number of hooks arranged in spirals in oblique rows, a double-walled proboscis receptacle, and an absence of spines on the trunk and to the Order Oligacanthorhynchida because they have a proboscis with a small number of hooks and an extremely short, double-walled proboscis receptacle that is not inserted in the anterior region of the body, according to descriptions by Amin (1987).

The only family in Order Oligacanthorhynchida is Oligacanthorhynchidae (SOUTHWELL \& MACFIE, 1925), which has a globular proboscis with a small number of hooks, a double-walled receptacle and six oblique rows, similar to what was observed here in the specimens parasitizing $A$. ameiva ameiva. Family Oligacanthorhynchidae contains twelve genera: Prosthenorchis Travassos, 1915; Oligacanthorhynchus Travassos, 1915; Macracanthorhynchus Travassos, 1917; Oncicola Travassos, 1916; Echinopardalis Travassos, 1918; Pachysentis Meyer, 1931; Nephridiorhynchus Meyer, 1931; Tchadorhynchus Troncy, 1970; Neoncicola Schmidt, 1972; Multisentis Smales, 1997, Cucullanorhynchus Amin, Van Ha and Heckmann, 2008 and Paraprosthenorchis Amin, Van Ha and Heckmann, 2008 (SCHMIDT, 1972; NICKOL \& DUNAGAN, 1989; SMALES, 1997; AMIN et al., 2008). According to Ávila \& Silva (2010), Oligacanthorhynchus is the only member of the family known to parasitize lizards from the genus Ameiva.

The cystacanths found in this study have six oblique rows with eight hooks, each with three morphological types, for a total of 48 hooks in the proboscis. This trait differs from Oligacanthorhynchus, which, according to Schmidt (1972), is characterized by six series with six hooks each in the proboscis for a total of 36 hooks.

Among the genera of Family Oligacanthorhynchidae, the cystacanths described here are most similar to the genus Pachysentis. According to Machado-Filho (1940), representatives of this genus have a proboscis with five to seven rows of five to eight hooks each, of three morphological types, for a total of 30 to 48 hooks on the proboscis. Within the genus Pachysentis, the cystacanths studied here are similar to those found in Pachysentis lenti (MACHADO-FILHO, 1940) and Pachysentis dollfusi (MACHADO-FILHO, 1940), which have a total of 48 hooks on the proboscis.

The cystacanths from $A$. ameiva ameiva are similar to specimens of $P$. lenti due to the dimensions of the morphological traits of the proboscis. Machado-Filho (1940) considered the proboscis to be the best character for identifying $P$. lenti, but other aspects, such as the size of the testes and the bursa are also considered in the literature to be important for defining the species. However, the specimen studied here was a juvenile, it is not possible to verify the identity.

According to Schmidt (1972), Family Oligacanthorhynchidae has a difficult and confusing system for characterization, particularly in the definition of its genera. Such difficulty arises because the traits of the proboscis apparatus, such as the shape and positioning of the hooks, are very similar between genera during the juvenile stage. Schmidt (1972) also states that accurate identification specimens of Oligacanthorhynchidae requires the analysis of traits that are not yet evident in the juvenile stage, such as the location of the testes and the shape of the trunk.

Conversely, Machado-Filho (1940) and Richardson (2005) state that cystacanth genera in Family Oligacanthorhynchidae can be identified easily through the morphological analysis and morphometry of the proboscis and its hooks. These authors cite that the structures of the proboscis are maintained (morphologically and morphometrically) throughout cystacanth development to the adult stage.

Elkins and Nickol (1983) characterized the forms of juvenile Oligacanthorhynchidae by following an experimental infection cycle induced in the laboratory from the juvenile to the adult stages. 

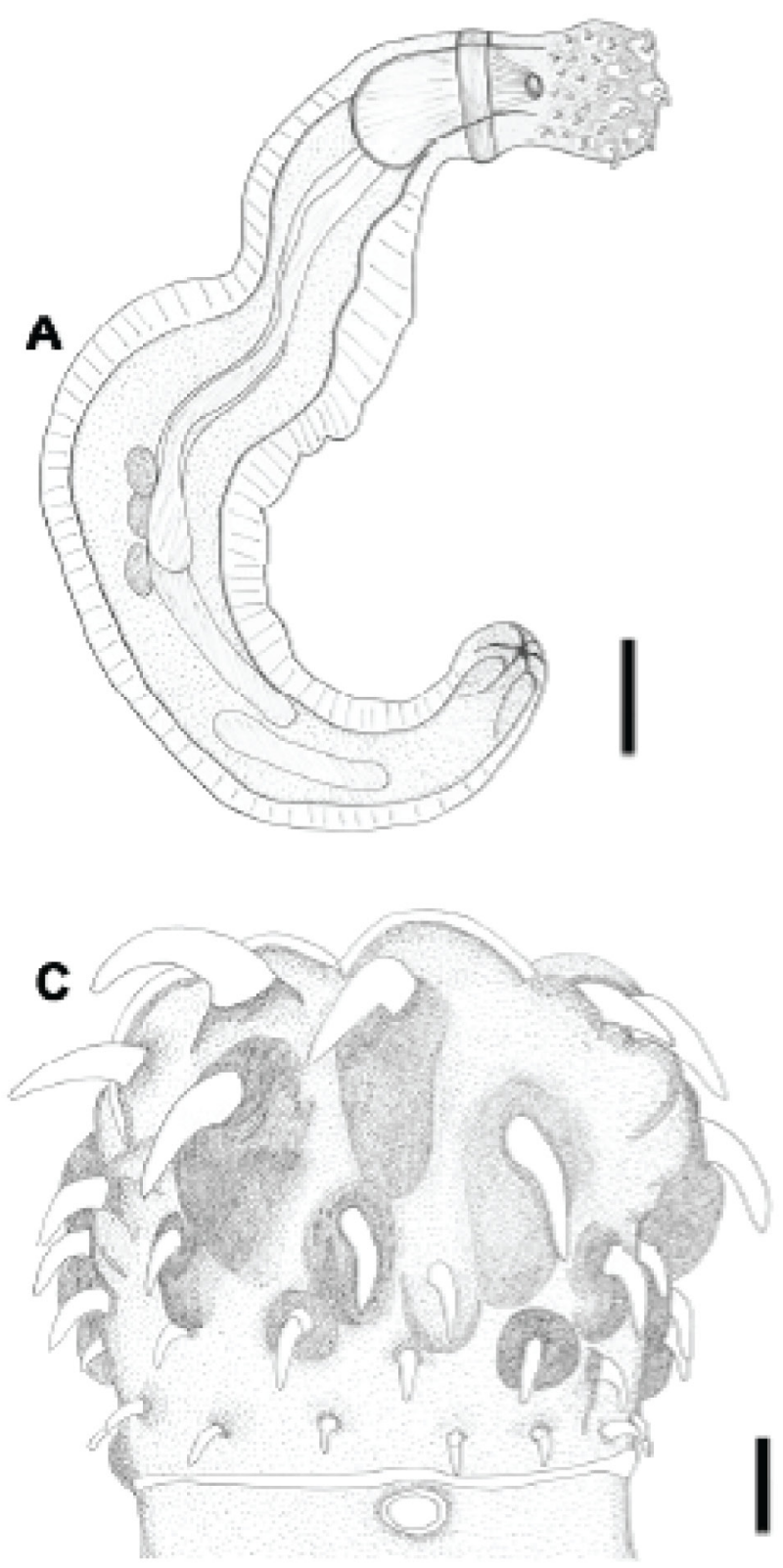
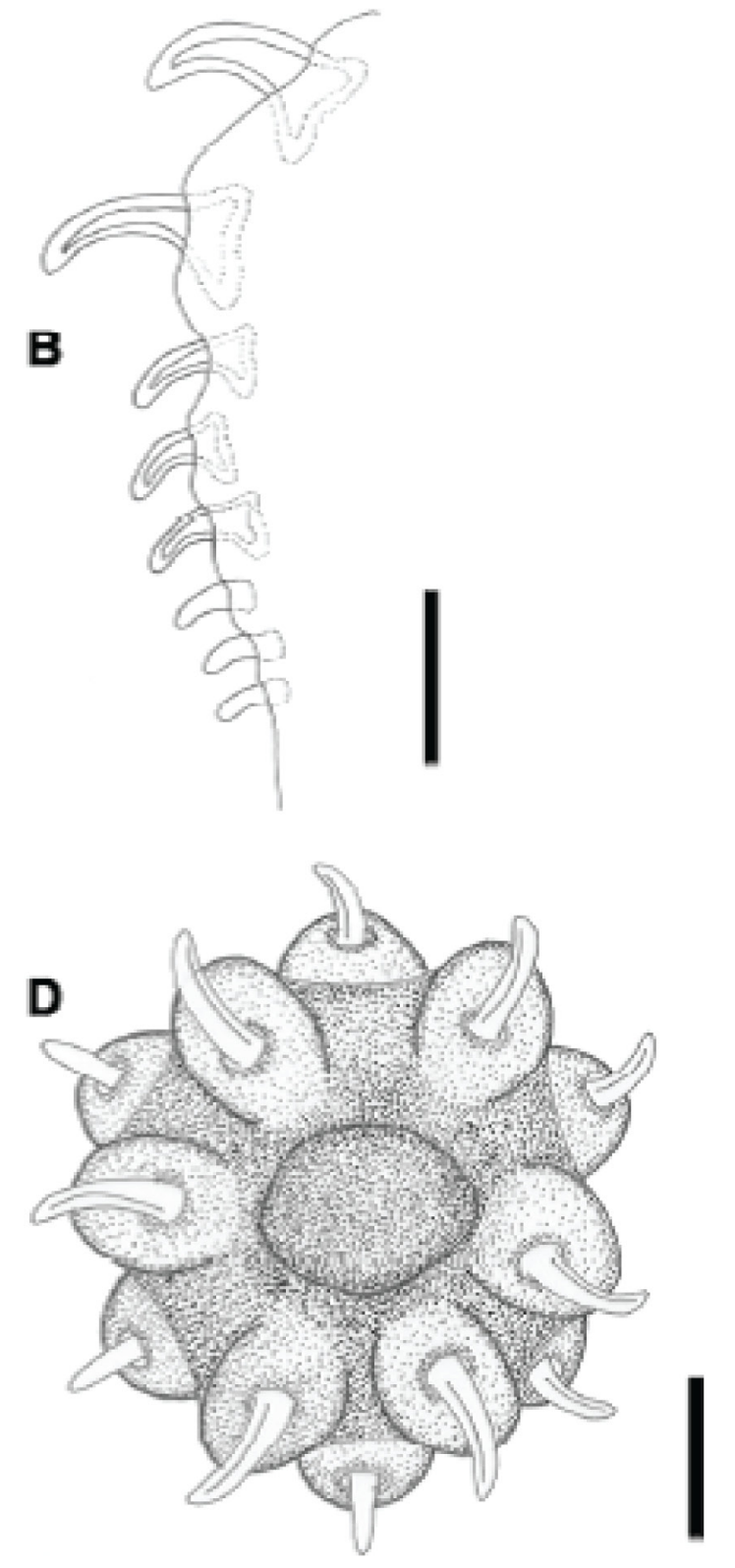

Figure 1. Taxonomic illustration of an Oligacanthorhynchidae cystacanth present in the visceral peritoneum of Ameiva ameiva ameiva. (A) Overview of the body. Observe the well-developed proboscis, presence of proboscis receptacle and reproductive organsprimordia $(\mathrm{Bar}=600 \mu \mathrm{m})$; (B) Schematic of one of the six series of eight proboscis hooks (Bar $=150 \mu \mathrm{m})$; (C) Lateral view of the globular proboscis. Note the first two large hooks at the apex of the proboscis, three medium-sized hooks and last three small hooks near the base of the proboscis. Cervix below the series of hooks, followed by insertion of the proboscis retractor muscle (Bar $=100 \mu \mathrm{m})$; (D) Upper front view of the proboscis. Note the helical arrangement of the first two rows of large hooks $(\mathrm{Bar}=150 \mu \mathrm{m})$.

Obviously, experimental infections of cystacanth larvae collected from scientific collections is impossible, and the process of fixing the host specimens in formaldehyde impedes the characterization of the larval stages, as well as the adults, of Acanthocephala fixed in loco (it makes analysis difficult by inhibiting the eversion of the proboscis).

Therefore, in light of the similarity between the genera within Oligacanthorhynchidae and the insufficient number of specimens found with exposed proboscises, we believe that the characterization of the cystacanth larvae found in the visceral peritoneum of A. ameiva ameiva from the MPEG Herpetology Collection is impossible, despite their similarity with the genus Pachysentis.

To ensure accurate identification, we believe that live hosts must be captured to obtain live cystacanths for morphological identification, molecular characterization and, when possible, experimental infection to obtain adult helminths. 

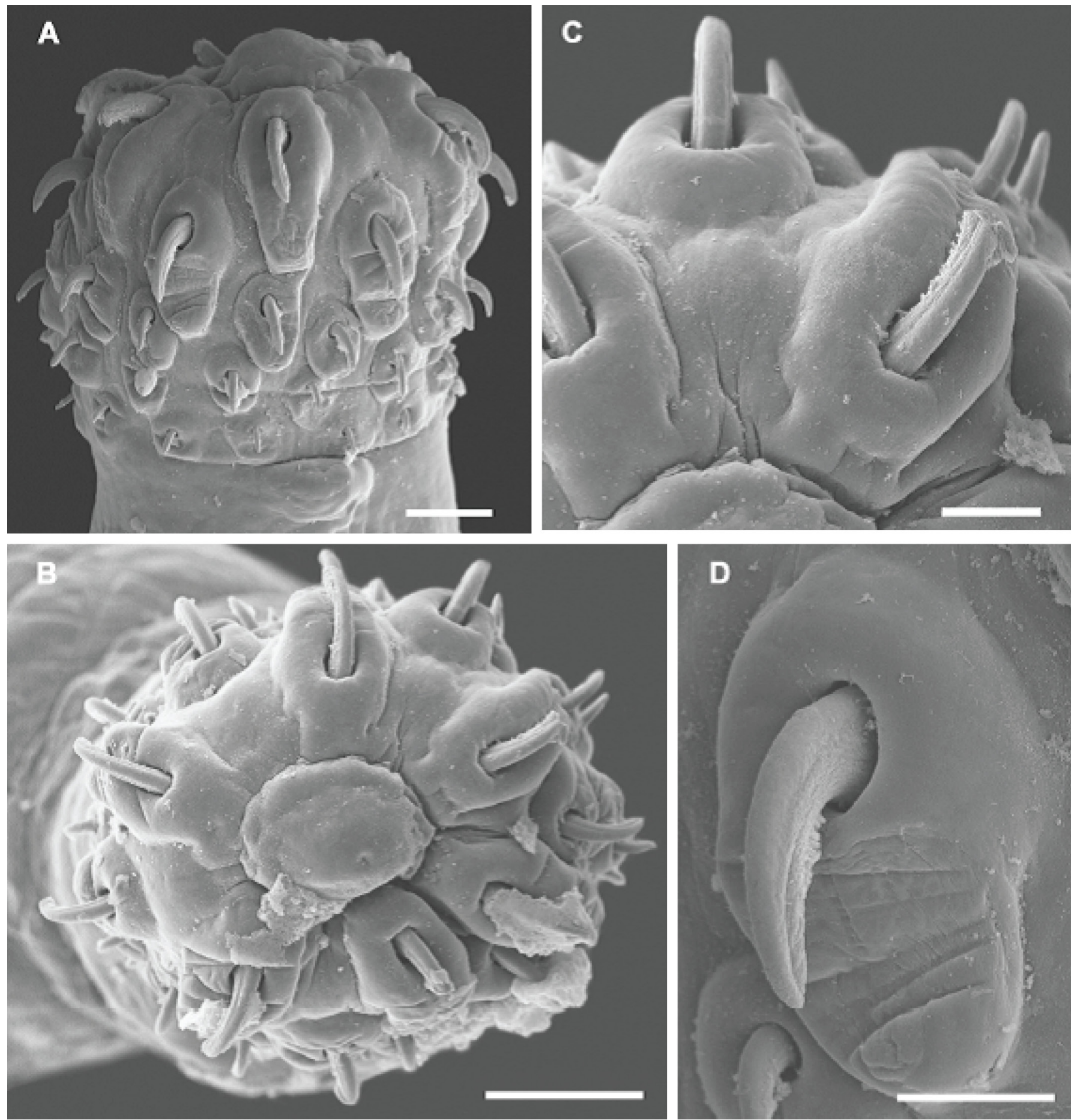

Figure 2. Scanning Electron Microscopy of an Oligacanthorhynchidae cystacanth proboscis found in the visceral peritoneum of Ameiva ameiva ameiva. (A) Lateral view of the proboscis detailing the globular shape of the proboscis and the general arrangement of the hooks $(\mathrm{Bar}=100 \mu \mathrm{m})$; (B) Upper front view of the proboscis $(\mathrm{Bar}=150 \mu \mathrm{m})$; (C) Partial upper front view of two hooks from the first two rows of the proboscis (Bar $=50 \mu \mathrm{m})$; (D) Detail of one of the hooks of the second row. Note the area of insertion of the hook in the proboscis $($ Bar $=50 \mu \mathrm{m})$.

Several authors, including Goldberg et al. (1998) and McAllister and Bursey (2007), also chose to only characterize Oligacanthorhynchidae cystacanths found in the body cavity of reptiles to the family level. Identification of cystacanths from the Oligacanthorhynchidae in $A$. ameiva ameiva from FLONA Caxiuanã (Portel - PA) allowed us to confirm parasitism in these lizards in eastern Amazonia.

\section{Acknowledgements}

We thank Dr. Ana Lúcia da Costa Prudente of the Emílio Goeldi Museum for the host material and Dr. Hilton Túlio Costi of the MPEG Electron Microscope Laboratory. This study was financially supported by PAPQ-PROPESP/UFPA, PROCAD NF 2009/CAPES, SISBiota-2010/MCT/CNPq; and CNPq-Productivity 
scholarship of SANTOS, JN. This work is part of Doctoral thesis of MACEDO, LC developed in the Post Graduate Program in Biology of Infectious and Parasitic of the ICB-UFPA.

\section{References}

Amato JFR, Boeger WA, Amato SB. Protocolo para laboratório: coleta e processamento de parasitas do pescado. Rio de Janeiro: Imprensa Universitária UFRRJ; 1991.

Amin OM, van Ha N, Heckmann RA. New and already known acanthocephalans mostly from mammals in Vietnam, with descriptions of two new genera and species in Archiacanthocephala. J Parasitol 2008; 94(1): 194-201. http://dx.doi.org/10.1645/GE-1394.1. PMid:18372641.

Amin OM. Classification of the Acanthocephala. Folia Parasitol (Praha) 2013; 60(4): 273-305. http://dx.doi.org/10.14411/fp.2013.031. PMid:24261131.

Amin OM. Key to the families and subfamilies of Acanthocephala, with the erection of a new class (Polyacanthocephala) and a new order (Polyacanthorhynchida). J Parasitol 1987; 73(6): 1216-1219. http:// dx.doi.org/10.2307/3282307. PMid:3437357.

Ávila RW, Silva RJ. Checklist of helminths from lizards and amphisbaenians (Reptilia, Squamata) of South America. J Venom Anim Toxins Incl Trop Dis 2010; 16(4): 543-572. http://dx.doi.org/10.1590/S167891992010000400005.

Ávila-Pires TCS. Lizards of the brazilian Amazonian (Reptilia: Squamata). Zool Verh 1995; 299(1): 1-706.

Elkins CA, Nickol BB. The epizootiology of Macracanthorhynchus ingens in Louisiana. J Parasitol 1983; 69(5): 951-956. http://dx.doi. org/10.2307/3281063.

Giese EG, Furtado AP, Lanfredi RM, Santos JN. A new cucullanid species (Nematoda) from Ageneiosus ucayalensis Castelnau, 1855 (Pisces: Auchenipteridae) from Pará, Brazil. J Parasitol 2010; 96(2): 389-394. http://dx.doi.org/10.1645/GE-2081.1. PMid:19954256.

Giugliano LG, Nogueira CC, Valdujo PH, Collevatti RG, Colli GR. Cryptic diversity in South American Teiinae (Squamata, Teiidae) lizards. Zool Scr 2013; 42(5): 473-487. http://dx.doi.org/10.1111/zsc.12017.

Goldberg SR, Bursey CR, Holshuh HJ. Prevalence and distribution of cystacanths of an oligacanthorhynchid acanthocephalan from the longnose snake, Rhinocheilus lecontei (Colubridae) in southwestern North America. J Helminthol Soc Wash 1998; 65(2): 262-265.

Harvey MB, Ugueto GN, Gutberlet RL Jr. Review of teiid morphology with a revised taxonomy and phylogeny of the Teiidae (Lepidosauria: Squamata). Zootaxa 2012; 3459: 1-156.

Machado-Filho DA. Pesquisas helmintológicas realizadas no Estado de Mato Grosso - Acanthocephala. Mem Inst Oswaldo Cruz 1940; 35(3): 593-601. http://dx.doi.org/10.1590/S0074-02761940000300011.

McAllister CT, Bursey CR. First report of the nematode, Physaloptera squamatae (Spirurida: Physalopteridae) in Oklahoma, with a summary of hosts. Proc Okla Acad Sci 2007; 87: 65-67.

Nickol BB, Dunagan TT. Reconsideration of the Acanthocephalan genus Echinopardalis, with a description of adult E. atrata and a key to the genera of the Oligacanthorhynchidae. Proc Helminthol Soc Wash 1989; 56(1): 8-13.

Ribas SC, Rocha CFD, Teixeira-Filho PF, Vicente JJ. Nematode infection in two sympatric lizards (Tropidurus torquatus and Ameiva ameiva) with different foraging tactics. Amphib-reptil 1998; 19(3): 323-330. http:// dx.doi.org/10.1163/156853898X00232.

Richardson DJ. Identification of cystacanths and adults of Oligacanthorhynchus tortuosa, Macracanthorhynchus ingens, and Macracanthorhynchus hirudinaceus based on proboscis and hook morphometrics. J Arkansas Acad Sci 2005; 59: 205-210.

Roberts LS, Janovy J Jr. Foundations of Parasitology. 8th ed. Dubuque: McGraw-Hill; 2009.

Schmidt GD. Development and life cycles. In: Crompton DWT, Nickol BB. Biology of the Acanthocephala. Cambridge: Cambridge University Press; 1985. p. 273-305.

Schmidt GD. Revision of the class Archiacanthocephala Meyer, 1931 (Phylum Acanthocephala), with emphasis on Oligacanthorhynchidae Southwell \& Macfie, 1925. J Parasitol 1972; 58(2): 290-297. http:// dx.doi.org/10.2307/3278091. PMid:5022866.

Smales LR. Multisentis myrmecobius, gen. et sp. nov. (Acanthocephala: Oligacanthorhynchidae) from the numbat, Myrmecobius fasciatus, and a key to genera of the Oligacanthorhynchidae. Invertebr Taxon 1997; 11(2): 301-307. http://dx.doi.org/10.1071/IT95023.

Southwell T, Macfie JWS. On a collection of Acanthocephala in the Liverpool School of Tropical Medicine. Ann Trop Med Parasitol 1925; 19(2): 141-184. 